\title{
Empiric therapy for hospital-acquired, Gram- negative complicated intra-abdominal infection and complicated urinary tract infections: a systematic literature review of current and emerging treatment options
}

Yoav Golan

\begin{abstract}
Background: Empiric therapy for healthcare-associated infections remains challenging, especially with the continued development of Gram-negative organisms producing extended-spectrum $\beta$-lactamases (ESBLs) and the threat of multi-drug-resistant organisms. Current treatment options for resistant Gram-negative infections include carbapenems, tigecycline, piperacillin-tazobactam, cefepime, ceftazidime, and two recently approved therapies, ceftolozane-tazobactam and ceftazidime-avibactam.

Methods: This systematic literature review surveys the published clinical trial evidence available since 2000 in support of both current and emerging treatment options in the settings of complicated intra-abdominal infection (CIAI) and complicated urinary tract infection (CUTI). When available, clinical cure rates for patients with infections from ESBL-producing strains are provided, as is information about efficacy against Pseudomonas aeruginosa.

Results: Clinical trial evidence to guide selection of empiric antibiotic therapy in patients with complicated, hospital-acquired, Gram-negative IAls and UTIs is limited. Though most of the clinical trials explored in this overview enrolled patients with complicated infections, often patients with severe infections and multiple comorbidities were excluded.

Conclusions: Practitioners in the clinical setting who are treating patients with complicated, hospital-acquired, Gram-negative IAIs and UTIs need to consider the possibility of polymicrobial infections, antibiotic-resistant organisms, and/or severely ill patients with multiple comorbidities. There is a severe shortage of evidence-based research to guide the selection of empiric antibiotic therapy for many patients in this setting. New therapies recently approved or in late-stage development promise to expand the number of options available for empiric therapy of these hospital-acquired, Gram-negative infections.
\end{abstract}

Keywords: Carbapenem, Piperacillin-tazobactam, Tigecycline, Ceftolozane-tazobactam, Ceftazidime-avibactam, Complicated intra-abdominal infection, Complicated urinary tract infection

Correspondence: ygolan@tuftsmedicalcenter.org

Tufts Medical Center, Department of Medicine, Division of Geographic

Medicine and Infectious Disease, 800 Washington St, Boston, MA 02446, USA 


\section{Background}

The increasing prevalence of bacterial infections with resistance to currently available antibiotics and the limited number of new antibiotics in development are now welldocumented $[1,2]$. This issue is especially acute for Gram-negative, healthcare-associated infections (HAIs), prompting the U.S. Centers for Disease Control and Prevention (CDC) to issue warnings regarding Gramnegative organisms, highlighting both the ability of these organisms to develop drug resistance and the scarcity of new treatments to combat them [3].

Antibiotic-resistant Gram-negative infections are especially prevalent in HAIs, accounting for about onequarter to one-third of such infections overall [4]. Gram-negative pathogens are frequently isolated from healthcare-acquired intra-abdominal infections (IAI) and urinary tract infections (UTIs) $[4,5]$. $\beta$-Lactam antibiotics are the traditional antibiotic class for infections caused by Gram-negative bacteria [3]. The highlyadaptive Gram-negative pathogens can produce various $\beta$-lactamase enzymes that render them resistant to the antibiotic's mechanism of action. Extended-spectrum $\beta$-lactamase (ESBL)-producing Gram-negative bacteria also tend to harbor resistance to several classes of non- $\beta$-lactam antibiotics, including fluoroquinolones, aminoglycosides, and trimethoprim-sulfamethoxazole [6]. As a consequence, these classes of antibiotics are generally associated with worse outcomes when treatment needs to account for the possibility of an ESBLproducing strain [7-10]. Carbapenems are generally recommended as first-line empiric therapy for Gramnegative infections in this case, and $\beta$-lactam $/ \beta$-lactamase-inhibitor combinations such as piperacillintazobactam are a second-line option $[8,10]$. However, the strength of evidence supporting these recommendations is variable. Recent clinical trials have supported the use of novel or third-generation cephalosporins in combination with a $\beta$-lactamase inhibitor in this setting.

Empiric therapy for Gram-negative HAIs needs to take into account local susceptibility data [10] as well as the risk for the presence of variousdrug-resistant strains. Of particular concern are ESBL-producing and carbapenemase-producing Enterobacteriaceae, as well as multi-drug-resistant Acinetobacter, and Pseudomonas aeruginosa [3, 6, 8]. Empiric therapy must balance the potential benefits of appropriate therapy with the potential for selection of resistant strains. The purpose of this review is to provide an overview of the clinical trial evidence supporting these established and emerging options for empiric therapy in patients with healthcare-associated complicated intraabdominal infections [cIAIs] or healthcare-associated complicated urinary tract infections [cUTIs] in which treatment must account for the risk of ESBL- producing Gram-negative pathogens and other multidrug-resistant Gram-negative strains as well as $P$. aeruginosa.

\section{Epidemiology}

In the United States, ESBL-producing and carbapenemresistant Enterobacteriaceae account for about 35,000 HAIs and 2300 deaths each year [3]. Between 2000 and 2009, the percentage of UTI infections from Escherichia coli and Klebsiella pneumoniae exhibiting ESBL production more than doubled (from $3.3 \%$ to $8.0 \%$ for E. coli and from $9.1 \%$ to $18.6 \%$ for K. pneumoniae) [11]. Overall, the frequency of UTI hospitalizations in the United States caused by resistant, Gram-negative pathogens increased by about $50 \%$ for multi-drug-resistant $P$. aeruginosa and by about $300 \%$ for ESBL-producing organisms [11]. The percentage of Enterobacteriaceae isolates from U.S. institutions exhibiting carbapenem resistance increased from $1.2 \%$ in 2001 to $4.2 \%$ in 2011, with Klebsiella species accounting for most of the increase [12]. Despite the relatively low incidence of infections from carbapenem-resistant $K$. pneumoniae, they are associated with high morbidity, mortality, and utilization of healthcare resources [13].

\section{Methods}

Literature searches were performed on PubMed using generic drug names (and alternative names) as primary search terms (Table 1). Results were filtered to include only phase 2,3 , and 4 clinical trials. In most cases, results were limited to trials published from 2000 to present. Publications were manually selected to include only trials of empiric therapy in adult patients with hospital-acquired cIAI or cUTI. In addition, to capture recent studies in pre-publication, abstracts from 2014 Infectious Disease Week (IDWeek) and the Interscience Conference on Antimicrobial Agents and Chemotherapy (ICAAC) were manually searched using the same criteria as above. Other studies known to the author were also included. Individual case study reports were not included (Fig. 1).

The systematic literature review yielded 16 clinical studies which were carried out during 2004 - 2014. A total of two clinical studies were identified via manual search of medical congress database presentations. All remaining clinical studies $(n=14)$ were published in peerreviewedmedical journals. Of these 14 published clinical trials, 13 studies explicitly reported that written informed consent was obtained for each patient and the protocol was reviewed and approved by an ethical review committee. Financial support was disclosed for all studies: all had received funding from the company that manufactured the antibiotic. A statement related to potential conflicts of interest was reported for 10 of the studies. 
Table 1 Criteria for scientific literature search related to current and emerging treatment options for hospital-acquired, gram-negative complicated intra-abdominal infection and complicated urinary tract infections

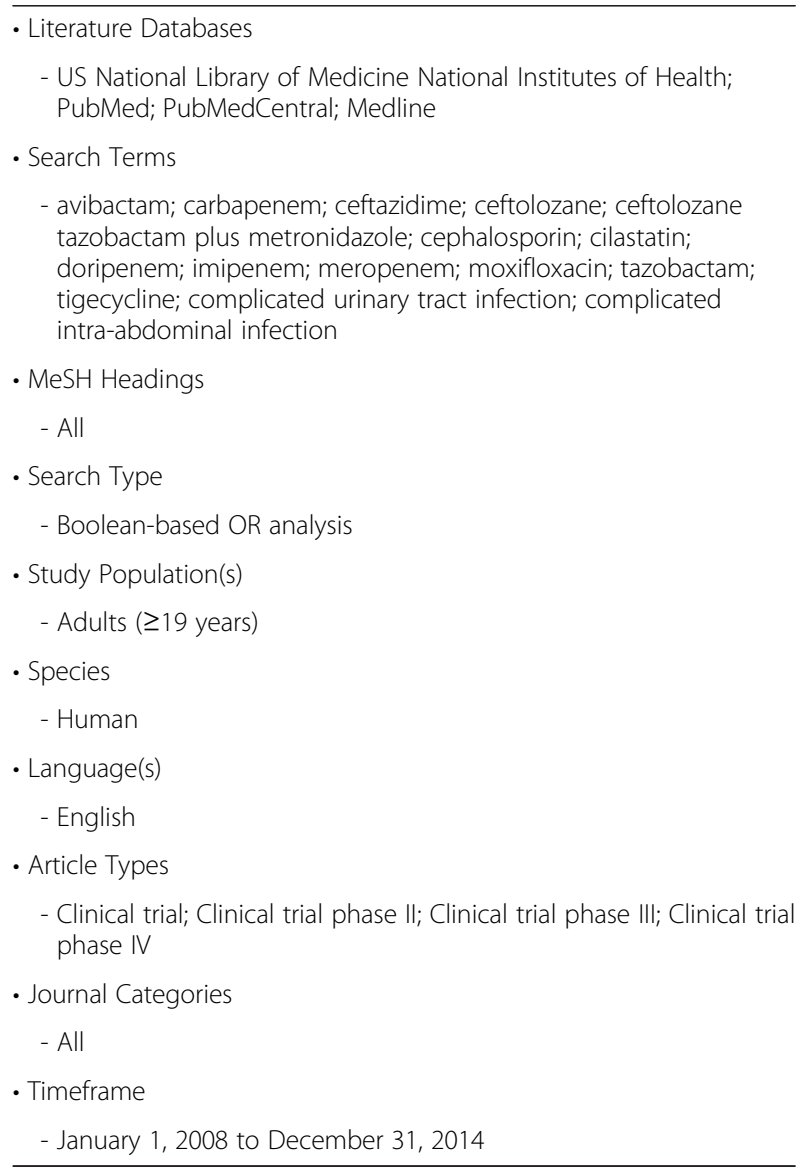

High-quality studies were defined as phase 3, randomized, controlled, double-blind trials or pooled analyses of such trials. Medium-quality studies include any phase 3 trials that substantially deviate from the high-quality definition (such as open-label or single-arm trials) as well as phase 2 trials. Low-quality studies include all other studies meeting the search criteria. Whenever sufficient high-quality data were available, low-quality studies were not included. Data was extracted manually. Unless otherwise noted, clinical cure rates at the test-of-cure (CCR-TOC) endpoint are given for the intent-to-treat population. The tables showing trial results are not intended for comparison of cure rates across trials, owing to differences in patient demographics and clinical characteristics, variation within trial design, as well as differences in the prevalence of Gram-negative organisms across different institutions, regions, and time epochs. Due to the paucity of data, potential sources of bias such as study sponsor, study design, study location, and number and type of study sites - were not considered in the design of this systematic literature review.

\section{Results}

Complicated intra-abdominal infection (cIAI)

Among the indications included in this overview, cIAI had the largest set of high- and medium-quality supporting trials. Key results are summarized in Table 2. Overall, use of the following therapies was supported by at least one high-quality trial: doripenem, meropenem, imipenemcilastatin, ertapenem, tigecycline, piperacillin-tazobactam, andceftolozane-tazobactam. However, the phase 3 ceftolozane-tazobactam trial is not yet published in a peerreviewed journal (as of February 2015). The newest option is ceftazidime-avibactam, a non- $\beta$-lactam $\beta$-lactamase inhibitor in combination with a late-generation cephalosporin, which is supported by medium-quality evidence from a phase 2 trial. In the high-quality trials, doripenem and ceftolozane-tazobactam provided the strongest evidence of efficacy against ESBL-producing strains and $P$. aeruginosa. Tigecycline was associated with significantly higher rates of nausea and vomiting vs. the comparator (imipenem-cilastatin). In one high-quality trial from 2003 (Study G, Table 1), ertapenem was associated with clinical cure in $73.1 \%(19 / 26)$ of patients with $P$. aeruginosa, although baseline isolates showed only $60 \%$ susceptibility [14]. In general, ertapenem does not have reliable efficacy against $P$. aeruginosa (see Discussion).

\section{Complicated urinary tract infection (cUTI)}

Only three high-quality and one medium-quality studies were found for treatment of cUTI (Table 3). High-quality trials support the use of doripenem (or levofloxacin). Two studies (three trials) found high clinical cure rates for doripenem, including activity in patients with levofloxacinresistant E. coli. Ceftolozane-tazobactam and levofloxacin had high clinical cure rates overall, but levofloxacin had low rates of microbiological eradication in patients with ESBL-producing Enterobacteriaceae or P. aeruginosa. A phase 2 trial supports the use of ceftazidime-avibactam plus metronidazole or imipenem-cilastatin.

\section{Discussion}

The overarching finding from this overview is that there is only sparse clinical trial evidence (since the year 2000) to guide selection of empiric antibiotic therapy in patients with complicated, hospital-acquired, Gram-negative IAIs and UTIs. Given that practitioners working in these settings frequently need to take into account the potential for polymicrobial infections, ESBL-producing organisms, and multi-drug-resistant Pseudomonas and other species, the evidence supporting therapy selection appears even less satisfactory. The inadequacy of the available evidence is further highlighted when severity of illness is considered. In the setting of hospital-acquired microbial infection, patients are often severely ill with multiple comorbidities. Most of the clinical trials explored in this overview, even though 


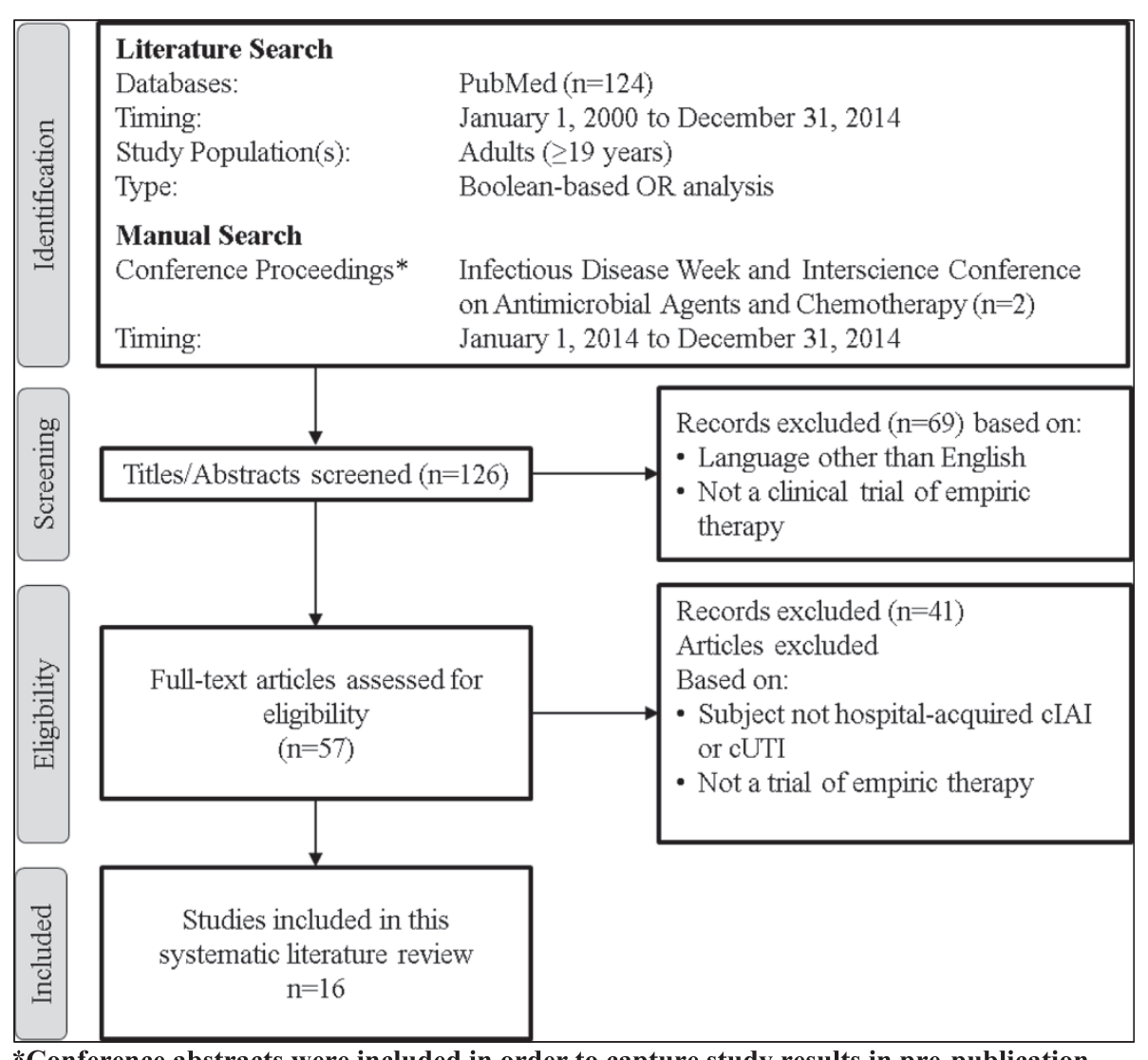

*Conference abstracts were included in order to capture study results in pre-publication

Fig. 1 Flow diagram of literature search and study selection

they enrolled patients with complicated infections, excluded patients with APACHE (Acute Physiology and Chronic Health Evaluation) II scores $>30$. Indeed, most of the trials had median APACHE II scores of 5-7, and patients were excluded on the basis of many common comorbid conditions. Thus, there is a severe shortage of evidence-based guidance on empirical antibiotic therapy for many patients with hospital-acquired, Gram-negative infections.

Considering the available evidence, the carbapenems in general-and doripenem in particular-are associated with the strongest set of high-quality trials. Doripenem, meropenem, imipenem-cilastatin, and ertapenem all had support from high-quality trials in the setting of cIAI, and doripenem also had support for use in cUTI. Carbapenems (sometimes in combination with another antibiotic) are active against most ESBL-producing strains and have been recommended as first-line therapy in critically ill patients with severe infections when there is a risk of ESBL-producing, Gram-negative bacteria $[1,8,10,15]$. However, they are susceptible to carbapenemases. Imipenem, meropenem, and doripenem are active against $P$. aeruginosa, although doripenem has a lower MIC and was superior to imipenem in that regard in patients with cIAI [16]. Ertapenem is not reliably active against $P$. aeruginosa [16]. Doripenem is less susceptible to certain carbapenemases compared with other carbapenems, although it is still susceptible to metallo- $\beta$ lactamase (MBL)-producing strains [17].

Tigecycline has broad-spectrum activity against both Gram-positive and Gram-negative bacteria, including activity against ESBL-producing strains. Its use in cIAI was associated with strong supporting evidence, although it was associated with significantly higher rates of nausea and vomiting. One medium-quality trial of tigecycline found high rates of clinical cure in patients with cIAI due to $P$. aeruginosa (Study F), but tigecycline is not reliably active against $P$. aeruginosa and its activity against Providencia and Proteus strains can be limited [18]. It has been widely studied for skin and skin-structure infections (not shown here) but has limited penetration into the urinary tract $[19,20]$; thus, there are limited data about its use for treatment of UTI. Current data do not support its use in severe infections. In a meta-analysis, tigecycline was associated with significantly higher rates of adverse events and numerically higher mortality than comparators [21]. U.S. prescribing information for tigecycline contains a blackbox warning about the increased mortality and indicating that its use should be reserved for situations when other treatments are not suitable. 
Table 2 Summary of studies in complicated intra-abdominal infection (clAl)

\begin{tabular}{|c|c|c|c|c|c|c|c|}
\hline \multirow[b]{2}{*}{ Index } & \multirow[b]{2}{*}{ Reference } & \multicolumn{2}{|l|}{ CCR-TOC } & \multirow[b]{2}{*}{ Description } & \multirow[b]{2}{*}{$\begin{array}{l}\text { Quality high }(H) \\
\text { or medium }(M)\end{array}$} & \multirow[b]{2}{*}{$\begin{array}{l}\text { Comparative } \\
\text { outcome } \\
\text { (A vs B) } \\
\end{array}$} & \multirow[b]{2}{*}{ Year } \\
\hline & & Agent A & Agent B & & & & \\
\hline$A$ & [27] & $\begin{array}{l}\text { Doripenem mlTT } \\
85.9 \%(140 / 163)\end{array}$ & $\begin{array}{l}\text { Meropenem mlTT } \\
85.3 \%(133 / 156)\end{array}$ & $R, D B, P 3$ & $\mathrm{H}$ & Noninferior & 2008 \\
\hline B & [28] & $\begin{array}{l}\text { Tigecycline } \\
86.1 \%(441 / 512)\end{array}$ & $\begin{array}{l}\text { Imipenem-cilastatin } \\
86.2 \%(442 / 513)\end{array}$ & $\begin{array}{l}\text { Pooled analysis of two } \\
\text { phase } 3 \text { trials. }\end{array}$ & $\mathrm{H}$ & Noninferior & 2005 \\
\hline C & [29] & $\begin{array}{l}\text { Tigecycline } \\
92.4 \%(219 / 237)\end{array}$ & $\begin{array}{l}\text { Imipenem-cilastatin } \\
88.8 \%(198 / 223)\end{array}$ & $\begin{array}{l}\text { Subanalysis of the } \\
\text { European data from } \\
\text { Study B }\end{array}$ & $\mathrm{H}$ & - & 2008 \\
\hline $\mathrm{D}$ & [30] & $\begin{array}{l}\text { Tigecycline } \\
80.6 \%(199 / 247)\end{array}$ & $\begin{array}{l}\text { Imipenem-cilastatin } \\
82.4 \%(210 / 255)\end{array}$ & $\mathrm{R}, \mathrm{DB}, \mathrm{P} 3$ & $\mathrm{H}$ & - & 2005 \\
\hline E & [31] & $\begin{array}{l}\text { Tigecycline mITT } \\
86.5 \%(45 / 52)\end{array}$ & $\begin{array}{l}\text { Imipenem-cilastatin mITT } \\
97.9 \%(47 / 48)\end{array}$ & $\mathrm{R}, \mathrm{OL}, \mathrm{P} 3$ & M & - & 2010 \\
\hline $\mathrm{F}$ & [32] & $\begin{array}{l}\text { Tigecycline } \\
81.8 \%(162 / 198)\end{array}$ & $\begin{array}{l}\text { Ceftriaxone-metronidazole } \\
79.4 \%(150 / 189)\end{array}$ & $\mathrm{R}, \mathrm{OL}$ & M & Noninferior & 2012 \\
\hline G & [14] & $\begin{array}{l}\text { Ertapenem } \\
79.3 \%(245 / 311)\end{array}$ & $\begin{array}{l}\text { Piperacillin-tazobactam } \\
76.2 \%(232 / 304)\end{array}$ & $R, D B, P 3$ & $\mathrm{H}$ & Equivalent & 2003 \\
\hline $\mathrm{H}$ & [33] & $\begin{array}{l}\text { Piperacillin-tazobactam "Clinical } \\
\text { success" } 97.3 \%(108 / 111)\end{array}$ & $\begin{array}{l}\text { Imipenem-cilastatin "Clinical } \\
\text { success" } 97.1 \%(100 / 103)\end{array}$ & $\mathrm{R}$ & $\mathrm{M} / \mathrm{H}$ & - & 2004 \\
\hline I & [34] & $\begin{array}{l}\text { Piperacillin-tazobactam followed } \\
\text { by amoxicillin clavulanate } \\
\text { For HAl: } 55 \%(17 / 31)\end{array}$ & $\begin{array}{l}\text { Moxifloxacin } \\
\text { For HAl: } 82 \%(22 / 27)\end{array}$ & $R, D B, P 3$ & M & & 2006 \\
\hline J & [35] & $\begin{array}{l}\text { Ceftolozane-tazobactam + } \\
\text { metronidazole } 91.4 \% \text { (64/70) }\end{array}$ & $\begin{array}{l}\text { Meropenem } \\
94.3 \%(33 / 35)\end{array}$ & $\mathrm{R}, \mathrm{DB}, \mathrm{P} 2$ & M & - & 2014 \\
\hline K & [36] & $\begin{array}{l}\text { Ceftolozane-tazobactam } \\
83.8 \%(399 / 476)\end{array}$ & $\begin{array}{l}\text { Meropenem } \\
85.8 \%(424 / 494)\end{array}$ & $R, D B, P 3$ & $\mathrm{H}$ & Noninferior & \\
\hline L & {$[37]$} & $\begin{array}{l}\text { Ceftazidime-avibactam + } \\
\text { metronidazole } \\
91.2 \%(62 / 68)\end{array}$ & $\begin{array}{l}\text { Meropenem } \\
93.4 \%(71 / 76)\end{array}$ & $\mathrm{R}, \mathrm{P} 2$ & M & - & 2013 \\
\hline
\end{tabular}

CCR-TOC clinical cure rate at the test-of-cure endpoint, $D B$ double-blind, HAI hospital-acquired infection, MIC minimum inhibitory concentration, mITT microbiologically evaluable intent-to-treat population, $O L$ open-label, $P 2$ phase $2, P 3$ phase $3, R$ randomized.

anless otherwise noted.

Piperacillin in combination with the $\beta$-lactamase inhibitor tazobactam is another treatment option; however, its use is mostly limited to mild infections or UTI. Most of the evidence supporting piperacillintazobactam comes from small trials, except for one phase 3 trial in cIAI in which it was used as a comparator against ertapenem. Even though piperacillintazobactam was associated with high rates of clinical response in patients with $P$. aeruginosa in that trial (Study G), additional coverage using aminoglycosides or colistin is usually considered necessary if $P$. aeruginosa is a potential pathogen [10].

The two newest antibiotics targeting treatment of suspected ESBL-producing, Gram-negative infections are ceftolozane-tazobactam and ceftazidime-avibactam [22, 23]. Ceftolozane is a novel cephalosporin with improved stability against AmpC $\beta$-lactamases [22], although coverage of AmpC-containing species is not uniform [24]. It has a lower MIC for $P$. aeruginosa compared with other thirdgeneration cephalosporins and its increased affinity to penicillin-binding proteins is thought to confer greater activity against resistant strains with efflux pumps or loss of porin channels [22]. Its use in combination with tazobactam confers greater activity against ESBL-producing Enterobacteriaceae [22]. However, it is not active against KPC-producing or MBL-producing strains. The two trials of ceftolozane-tazobactam (Studies J and O), to date available only in preliminary form, provide high-quality support for use of this therapy in patients with cIAI and cUTI.

Ceftazidime in combination with the non- $\beta$-lactam $\beta$-lactamase inhibitor avibactam is active against strains producing KPC or OXA-48 $\beta$-lactamases, as well as strains with carbapenem resistance owing to porin loss and production of an ESBL or AmpC $[25,26]$. In vitro studies found MIC $\leq 2 \mathrm{mcg} / \mathrm{mL}$ for ceftazidime-avibactam against 8 of 8 ceftazidime-resistant $K$. pneumoniae isolates with OXA-48, 15 of 15 isolates with combinations of impermeability and ESBLs or AmpC, and 7 of 10 isolates with KPC [25]. Avibactam inhibits Ambler class A and $C \beta$-lactamases and some class $\mathrm{D} \beta$-lactamases. Medium-quality trials support the efficacy for ceftazidime-avibactam in cIAI and cUTI, and phase 3 trials are ongoing. 
Table 3 Summary of studies in complicated urinary tract infection (cUTI)

\begin{tabular}{|c|c|c|c|c|c|c|c|}
\hline \multirow[b]{2}{*}{ Index } & \multirow[b]{2}{*}{ Reference } & \multicolumn{2}{|l|}{ CCR-TOC/ITT ${ }^{a}$} & \multirow[b]{2}{*}{ Description } & \multirow[b]{2}{*}{ Quality } & \multirow[b]{2}{*}{ Comparative outcome (A vs B) } & \multirow[b]{2}{*}{ Year } \\
\hline & & Agent A & Agent B & & & & \\
\hline $\bar{M}$ & {$[38]$} & $\begin{array}{l}\text { Doripenem } \\
95.1 \%(272 / 286)\end{array}$ & $\begin{array}{l}\text { Levofloxacin } \\
90.2 \%(240 / 266)\end{array}$ & $\mathrm{P} 3, \mathrm{R}$ & $\mathrm{H}$ & Noninferior & 2009 \\
\hline $\mathrm{N}$ & {$[39]$} & $\begin{array}{l}\text { Doripenem } \\
94.1 \%(511 / 543)\end{array}$ & $\begin{array}{l}\text { Levofloxacin } \\
90.2 \%(240 / 266)\end{array}$ & See comments & $\mathrm{H}$ & Noninferior & 2010 \\
\hline $\mathrm{O}$ & {$[40]$} & $\begin{array}{l}\text { Ceftolozane-tazobactam } \\
95.9 \%(327 / 341) \mathrm{ME}\end{array}$ & $\begin{array}{l}\text { Levofloxacin } \\
93.2 \%(329 / 353) \text { ME }\end{array}$ & $\mathrm{R}, \mathrm{DB}, \mathrm{P} 3$ & $\mathrm{H}$ & Noninferior & \\
\hline$P$ & [41] & $\begin{array}{l}\text { Ceftazidime-avibactam } \\
85.7 \%(24 / 28)\end{array}$ & $\begin{array}{l}\text { Imipenem-cilastatin } \\
80.6 \%(29 / 36)\end{array}$ & $P 2, D B, R$ & M & - & 2012 \\
\hline
\end{tabular}

$C C R$-TOC/ITT clinical cure rate at the test-of-cure endpoint intent-to-treat, DB double-blind, ME microbiological eradication, $O L$ open-label, $P 2$ phase $2, P 3$ phase 3 , $R$ randomized.

a Unless otherwise noted.

\section{Conclusions}

Clinical trial evidence is sparse regarding empiric antibiotic therapies for patients with hospital-acquired infections, when antibiotic therapy often needs to cover ESBLproducing strains, $P$. aeruginosa, and other multi-drug-resistant strains. Furthermore, the available clinical trial evidence is often incompatible with the clinical setting, in which patients have more severe illness or comorbidities excluded from clinical trials. Comparatively strong evidence exists for treatments in the setting of cIAI but the evidence in the setting of cUTI is small. When antibiotic therapy is necessary, current guidelines recommend empiric therapy using a carbapenem until definitive therapy can be selected. The limited clinical trial evidence supports this recommendation, although carbapenems differ in their coverage of $P$. aeruginosa and susceptibility to carbapenemases. Guidelines also recommend that choice of empiric therapy be tailored to account for knowledge of institutional and local susceptibility patterns. Unfortunately, clinical trials offer only scant information to aid in that aspect of decision making, leaving clinicians to rely on in vitro susceptibility testing.

\footnotetext{
Abbreviations

APACHE: Acute Physiology and Chronic Health Evaluation; CCR-TOC: Clinical cure rates at the test-of-cure; CDC: Centers for Disease Control and Prevention; cIAl: Complicated intra-abdominal infection; CUTI: Complicated urinary tract infection; DB: Double-blind; ESBL: Extended-spectrum $\beta$ lactamase; HAl: Healthcare-associated infection; IAI: Intra-abdominal infection; ICAAC: Interscience Conference on Antimicrobial Agents and Chemotherapy; IDWeek: Infectious Disease Week; ITT: Intent to treat; KPC: Klebsiella pneumoniae carbapenemase; MBL: Metallo- $\beta$-lactamase; MIC: Minimum inhibitory concentration; ME: Microbiological eradication; mITT: Microbiologically evaluable intent-to-treat population; OL: Open-label; UTI: Urinary tract infection.
}

\section{Competing interests}

Over the past two years Dr. Golan has: 1) served as a principle investigator in clinical trials performed by the following companies: Cubist pharmaceuticals. Merck Inc, Forest laboratories, Optimer Pharma, Actelion, Summit. 2) served as a consultant or advisor to Merck, Pfizer, Forest, Cubist, Theravance, Durata, Optimer. 3) received honorarium from Merck, Pfizer, Cubist, Forest, Optimer. I have not been employed by a pharma company and never owned stock of any Pharma company.

\section{Author's contributions}

YG was involved in drafting the manuscript and revising it critically for important intellectual content. Additionally, YG gave his final approval to submit the final draft of the manuscript.

\section{Acknowledgements}

This review article is sponsored by Forest Laboratories, LLC. Assistance with writing and manuscript preparations was provided by Ken Scholz, PhD, Susan Martin, PhD, and The Medicine Group. The author is entirely responsible for the scientific content of the paper.

\section{Article Summary}

Clinical trial evidence is limited regarding choice of empiric antibiotic therapy for hospital-acquired, Gram-negative infections, but new treatment options have become available recently or are in late-stage development.

\section{Funding Support}

Writing and editorial services for the preparation of this manuscript were provided by The Medicine Group, and funded by Forest Laboratories, LLC. The author confirms that they received no payment for the preparation of this manuscript, and take full accountability for the material presented.

Received: 23 March 2015 Accepted: 22 July 2015

Published online: 05 August 2015

\section{References}

1. Fair RJ, Tor $Y$. Antibiotics and bacterial resistance in the 21 st century. Perspect Med Chem. 2014;6:25-64.

2. Shlaes DM, Sahm D, Opiela C, Spellberg B. The FDA reboot of antibiotic development. Antimicrob Agents Chemother. 2013;57(10):4605-7.

3. Antibiotic resistance threats in the United States (2013) [http://www.cdc. gov/drugresistance/pdf/ar-threats-2013-508.pdf]

4. Sievert DM, Ricks P, Edwards JR, Schneider A, Patel J, Srinivasan A, et al. Antimicrobial-resistant pathogens associated with healthcare-associated infections: summary of data reported to the National Healthcare Safety Network at the Centers for Disease Control and Prevention, 2009-2010. Infect Control Hosp Epidemiol. 2013;34(1):1-14.

5. Swenson BR, Metzger R, Hedrick TL, McElearney ST, Evans HL, Smith RL, et al. Choosing antibiotics for intra-abdominal infections: what do we mean by "high risk"? Surg Infect (Larchmt). 2009;10(1):29-39.

6. Pitout JD, Laupland KB. Extended-spectrum beta-lactamase-producing Enterobacteriaceae: an emerging public-health concern. Lancet Infect Dis. 2008;8(3):159-66.

7. Endimiani A, Luzzaro F, Perilli M, Lombardi G, Coli A, Tamborini A, et al. Bacteremia due to Klebsiella pneumoniae isolates producing the TEM52 extended-spectrum beta-lactamase: treatment outcome of patients receiving imipenem or ciprofloxacin. Clin Infect Dis. 2004;38(2):243-51.

8. Kanj SS, Kanafani ZA. Current concepts in antimicrobial therapy against resistant Gram-negative organisms: extended-spectrum beta-lactamaseproducing Enterobacteriaceae, carbapenem-resistant Enterobacteriaceae, and multidrug-resistant Pseudomonas aeruginosa. Mayo Clin Proc. 2011;86(3):250-9. 
9. Rodriguez-Bano J, Navarro MD, Romero L, Muniain MA, de Cueto M, Rios MJ, et al. Bacteremia due to extended-spectrum beta -lactamaseproducing Escherichia coli in the CTX-M era: a new clinical challenge. Clin Infect Dis. 2006;43(11):1407-14.

10. Solomkin JS, Mazuski JE, Bradley JS, Rodvold KA, Goldstein EJ, Baron EJ, et al. Diagnosis and management of complicated intra-abdominal infection in adults and children: guidelines by the Surgical Infection Society and the Infectious Diseases Society of America. Clin Infect Dis. 2010;50(2):133-64.

11. Zilberberg MD, Shorr AF. Secular trends in Gram-negative resistance among urinary tract infection hospitalizations in the United States, 2000-2009. Infect Control Hosp Epidemiol. 2013;34(9):940-6.

12. Centers for Disease Control and Prevention (CDC). Vital signs: carbapenem-resistant Enterobacteriaceae. MMWR Morb Mortal Wkly Rep. 2013:62(9):165-70.

13. Patel TS, Nagel JL. Clinical Outcomes of Enterobacteriaceae Infections Stratified by Carbapenem MICs. J Clin Microbiol. 2015;53(1):201-5.

14. Solomkin JS, Yellin AE, Rotstein OD, Christou NV, Dellinger EP, Tellado JM, et al. Ertapenem versus piperacillin/tazobactam in the treatment of complicated intraabdominal infections: results of a double-blind randomized comparative phase III trial. Ann Surg. 2003;237(2):235-45.

15. Kollef MH, Golan Y, Micek ST, Shorr AF, Restrepo MI. Appraising contemporary strategies to combat multidrug resistant Gram-negative bacterial infections-proceedings and data from the Gram-Negative Resistance Summit. Clin Infect Dis. 2011;53 Suppl 2:S33-55. quiz S56-38.

16. Jones RN, Huynh HK, Biedenbach DJ, Fritsche TR, Sader HS. Doripenem (S-4661) a novel carbapenem: comparative activity against contemporary pathogens including bactericidal action and preliminary in vitro methods evaluations. J Antimicrob Chemother. 2004;54(1):144-54.

17. Mushtaq S, Ge Y, Livermore DM. Doripenem versus Pseudomonas aeruginosa in vitro: activity against characterized isolates, mutants, and transconjugants and resistance selection potential. Antimicrob Agents Chemother. 2004;48(8):3086-92.

18. Pankey GA. Tigecycline. J Antimicrob Chemother. 2005;56(3):470-80.

19. Falagas ME, Karageorgopoulos DE, Dimopoulos G. Clinical significance of the pharmacokinetic and pharmacodynamic characteristics of tigecycline. Curr Drug Metab. 2009:10(1):13-21.

20. Ellis-Grosse EJ, Babinchak T, Dartois N, Rose G, Loh E. The efficacy and safety of tigecycline in the treatment of skin and skin-structure infections: results of 2 double-blind phase 3 comparison studies with vancomycin-aztreonam. Clin Infect Dis. 2005;41 Suppl 5:S341-53.

21. Cai $Y$, Wang R, Liang B, Bai N, Liu Y. Systematic review and meta-analysis of the effectiveness and safety of tigecycline for treatment of infectious disease. Antimicrob Agents Chemother. 2011;55(3):1162-72.

22. Hong MC, Hsu DI, Bounthavong M. Ceftolozane/tazobactam: a novel antipseudomonal cephalosporin and beta-lactamase-inhibitor combination. Infec Drug Resistance. 2013;6:215-23.

23. Zhanel GG, Chung P, Adam H, Zelenitsky S, Denisuik A, Schweizer F, et al. Ceftolozane/tazobactam: a novel cephalosporin/beta-lactamase inhibitor combination with activity against multidrug-resistant Gram-negative bacilli. Drugs. 2014;74(1):31-51.

24. Farrell DJ, Flamm RK, Sader HS, Jones RN. Antimicrobial activity of ceftolozane-tazobactam tested against Enterobacteriaceae and Pseudomonas aeruginosa with various resistance patterns isolated in U.S. Hospitals (2011-2012). Antimicrob Agents Chemother 2013;57(12):6305-10.

25. Livermore DM, Mushtaq S, Warner M, Zhang J, Maharjan S, Doumith M, et al. Activities of NXL104 combinations with ceftazidime and aztreonam against carbapenemase-Producing Enterobacteriaceae. Antimicrob Agents Chemother. 2011;55(1):390-4.

26. Zhanel GG, Lawson CD, Adam H, Schweizer F, Zelenitsky S, Lagace-Wiens PR, et al. Ceftazidime-avibactam: a novel cephalosporin/beta-lactamase inhibitor combination. Drugs. 2013;73(2):159-77.

27. Lucasti C, Jasovich A, Umeh O, Jiang J, Kaniga K, Friedland I. Efficacy and tolerability of IV doripenem versus meropenem in adults with complicated intra-abdominal infection: a phase III, prospective, multicenter, randomized, double-blind, noninferiority study. Clin Ther. 2008;30(5):868-83.

28. Babinchak T, Ellis-Grosse E, Dartois N, Rose GM, Loh E. Tigecycline 301 Study Group, Tigecycline 306 Study Group: The efficacy and safety of tigecycline for the treatment of complicated intra-abdominal infections: analysis of pooled clinical trial data. Clin Infect Dis. 2005;41 Suppl 5:S354-67.
29. Fomin P, Koalov S, Cooper A, Babinchak T, Dartois N, De Vane N, et al. The efficacy and safety of tigecycline for the treatment of complicated intraabdominal infections - the European experience. J Chemother. 2008;20 Suppl 1:12-9.

30. Oliva ME, Rekha A, Yellin A, Pasternak J, Campos M, Rose GM, et al. A multicenter trial of the efficacy and safety of tigecycline versus imipenem/ cilastatin in patients with complicated intra-abdominal infections [Study ID Numbers: 3074A1-301-WW; ClinicalTrials.gov Identifier: NCT00081744]. BMC Infect Dis. 2005;5:88.

31. Chen Z, Wu J, Zhang Y, Wei J, Leng X, Bi J, et al. Efficacy and safety of tigecycline monotherapy vs. imipenem/cilastatin in Chinese patients with complicated intra-abdominal infections: a randomized controlled trial. BMC Infect Dis. 2010;10:217.

32. Qvist N, Warren B, Leister-Tebbe H, Zito ET, Pedersen R, McGovern PC, et al. Efficacy of tigecycline versus ceftriaxone plus metronidazole for the treatment of complicated intra-abdominal infections: results from a randomized, controlled trial. Surg Infect (Larchmt). 2012;13(2):102-9.

33. Erasmo AA, Crisostomo AC, Yan LN, Hong YS, Lee KU, Lo CM. Randomized comparison of piperacillin/tazobactam versus imipenem/cilastatin in the treatment of patients with intra-abdominal infection. Asian J Surg. 2004;27(3):227-35

34. Malangoni MA, Song J, Herrington J, Choudhri S, Pertel P. Randomized controlled trial of moxifloxacin compared with piperacillin-tazobactam and amoxicillin-clavulanate for the treatment of complicated intra-abdominal infections. Ann Surg. 2006;244(2):204-11.

35. Lucasti C, Hershberger E, Miller B, Yankelev S, Steenbergen J, Friedland I, et al. Multicenter, double-blind, randomized, phase II trial to assess the safety and efficacy of ceftolozane-tazobactam plus metronidazole compared with meropenem in adult patients with complicated intra-abdominal infections. Antimicrob Agents Chemother. 2014;58(9):5350-7.

36. Eckmann C, Hershberger E, Miller B, Wooley M, Friedland I, Steenbergen J, Collins S, Yuan G, Barie P, Solomkin J: P0266a. Efficacy and safety of ceftolozane/ tazobactam versus meropenem in the treatment of complicated intra-abdominal infections (CIAI) in hospitalised adults: results from the phase 3 aspect-c|AI trial. [Abstract] In: 24th Annual European Congress of Clinical Microbiology and Infectious Diseases: May 10-13 2014; Barcelona, Spain; 2014. https://www.escmid. org/escmid_library/online_lecture_library/?search=1\&current_page=1\&search_ term=Christian+Eckmann Accessed 7/30/201

37. Lucasti C, Popescu I, Ramesh MK, Lipka J, Sable C. Comparative study of the efficacy and safety of ceftazidime/avibactam plus metronidazole versus meropenem in the treatment of complicated intra-abdominal infections in hospitalized adults: results of a randomized, double-blind, phase II trial. J Antimicrob Chemother. 2013;68(5):1183-92.

38. Naber KG, Llorens L, Kaniga K, Kotey P, Hedrich D, Redman R. Intravenous doripenem at 500 milligrams versus levofloxacin at 250 milligrams, with an option to switch to oral therapy, for treatment of complicated lower urinary tract infection and pyelonephritis. Antimicrob Agents Chemother. 2009;53(9):3782-92.

39. Redman R, Damiao R, Kotey P, Kaniga K, Davies T, Naber KG. Safety and efficacy of intravenous doripenem for the treatment of complicated urinary tract infections and pyelonephritis. J Chemother. 2010;22(6):384-91.

40. Wagenlehner F, Umeh O, Huntington J, Cloutier D, Friedland I, Steenbergen J, Yuan G, Yoon M, Darouiche R: eP449. Efficacy and safety of ceftolozane/ tazobactam versus levofloxacin in the treatment of complicated urinary tract infections (CUTI)/pyelonephritis in hospitalised adults: results from the phase 3 aspect-CUTI trial. [Abstract] In: 24th Annual European Congress of Clinical Microbiology and Infectious Diseases: May 10-13 2014; Barcelona, Spain; 2014. https://www.escmid.org/escmid_library/online_lecture_library/ ?search=1\&current_page=1\&search_term=eP449https://www.escmid.org/ escmid_library/online_lecture_library/?search=1\&current_page=1\&search_ term $=\bar{e}$ P449. Accessed 7/30/2015

41. Vazquez JA, Gonzalez Patzan LD, Stricklin D, Duttaroy DD, Kreidly Z, Lipka J, et al. Efficacy and safety of ceftazidime-avibactam versus imipenemcilastatin in the treatment of complicated urinary tract infections, including acute pyelonephritis, in hospitalized adults: results of a prospective, investigator-blinded, randomized study. Curr Med Res Opin. 2012;28(12):1921-31. 